\title{
A educação escolar primária na Primeira República (1889-1929)
}

\section{Primary School education in the First Republic (1889- 1929)}

\section{La educación escolar primaria en la Primera República (1889-1929)}

\author{
Ednéia Regina Rossi ${ }^{1}$
}

DOI: http://dx.doi.org/10.20435/serie-estudos.v22i45.1048

\begin{abstract}
Resumo: Este artigo se propõe a refletir sobre a relação entre os projetos educacionais da Primeira República no Brasil (1899-1929) e o pensamento moderno e iluminista. A Primeira República se caracterizou pela implantação de reformas de ensino em diferentes estados brasileiros. Esses projetos, embora possuíssem particularidades de estado para estado, em termos gerais, partilharam do ideal de normalizar, profissionalizar e sistematizar a escolarização das camadas populares. Em termos de finalidades formativas, a escola possuía objetivos explícitos de aculturação e socialização. Por meio dela, por exemplo, as crianças se tornariam homens e mulheres com sentimentos nacionais e subjugados à autoridade não pelo temor, mas pela razão que julga e decide. Esse novo mecanismo de controle, feito de racionalidade, a ser desenvolvido pela escola, pode ser observado nas intenções estruturadoras da escola primária e nos conhecimentos por ela transmitidos. Ao mesmo tempo, esses projetos intencionavam homogeneizar costumes, hábitos e quereres, delineando um sistema de ensino dirigido e controlado, de forma a produzir a unificação da nação brasileira e produzir a equidade requerida pela democracia moderna.
\end{abstract}

Palavras-chave: história da educação brasileira; Primeira República e modernidade; educação homogeneizadora e soberania.

Abstract: This article aims to reflect about the relation between educational projects in the First Brazilian Republic (1899-1929) and modern and enlightened thinking. The First Republic was characterized by the implementation of educational reforms in different Brazilian States. These projects, although having particularities from state to state, in general terms, shared the ideal of normalizing, professionalizing and systemizing the schooling of the popular classes. In terms of formative purposes, the school had explicit acculturation and socialization goals. By means of the school, for example, children would become adult men and women with national feelings and subdued to authority not by means of fear, but by the reason that judges and decides. This new control mechanism, made of rationality, to be developed by the school, can be observed in the structuring intentions of primary school and on the knowledge by it transmitted. At the same time, these projects intended to homogenize mores, habits and desires, outlining a directed and controlled education system, thus producing unification of the

${ }^{1}$ Universidade Estadual de Maringá (UEM), Maringá, Paraná, Brasil.. 
Brazilian Nation and producing the required equity by modern democracy.

Key words: History of Brazilian Education; First Republic and modernity; Homogenized Education and sovereignty.

Resumen: Este artículo tiene como objetivo reflexionar sobre la relación entre los proyectos educativos de la Primera República en Brasil (1899-1929) y el pensamiento moderno e iluminista. La Primera República se caracterizó por la aplicación de reformas educativas en diferentes estados brasileños. Estos proyectos, aunque que tuvieran diferentes características de un estado a otro, en general, compartieron el ideal de normalizar, profesionalizar y sistematizar la escolaridad de las clases populares. Con respecto a las finalidades de formación, la escuela tenía objetivos explícitos de la aculturación y socialización. A través de ella, por ejemplo, los niños se convertirían en hombres y mujeres con sentimientos nacionalistas y sometidos a la autoridad, no por el miedo sino por la razón que juzga y decide. Este nuevo mecanismo de control, racional, que será desarrollado por la escuela se evidencia en las intenciones de la estructuración de la escuela primaria y en el conocimiento por ella transmitido. Al mismo tiempo, estos proyectos tenian la intención de homogenizar costumbres, hábitos y anhelos, bosquejando un sistema de educación orientada y controlada, con el objetivo de alcanzar la unificación de la nación brasileña y la equidad requerida por la democracia moderna.

Palabras clave: historia de la educación brasileña; Primera República y modernidad; educación para unificación y soberanía.

Pode-se falar sobre a educação escolar na Primeira República no Brasil (18891929) priorizando diferentes problemáticas. Para este texto proponho refletir sobre a relação entre os projetos educacionais da Primeira República brasileira e o pensamento moderno. Tomemos, como exemplo, o propósito de formação do povo, presente no plano de organização da instrução pública, proposto pela Comissão de Educação da Assembleia Legislativa durante a Revolução Francesa (1789). Com o plano de instrução pública, pretendia-se criar o homem novo, produzir uma pátria regenerada capaz de efetivar os princípios de uma sociedade democrática. A escolarização despontava como um dos veículos prioritários na construção da nacionalidade. Tratavase de um plano para a composição de uma escola nacional, tal como o século XIX iria constituí-la. Os princípios deflagrados por aquele plano, sobretudo, tornaram-se uma referência pedagógica da qual nos sentimos herdeiros, especialmente quando, no coletivo, expressamos a defesa da escola pública, universal, única para todos e gratuita. A inspiração para esse plano adveio da efervescência intelectual do século XVIII, o qual, não por acaso, ficou conhecido como o século das luzes ou da ilustração. 


\section{SÉCULO DAS LUZES E A SUA RELAÇÃO COM OS PROJETOS EDUCACIONAIS DA PRIMEIRA REPÚBLICA}

O século das luzes adquiriu esse epíteto por ter calcado um crédito sem igual na capacidade da educação em retirar o indivíduo da menoridade. "A menoridade é a incapacidade de se servir do entendimento sem a orientação de outrem" (KANT, 1989, p. 11).

Para o lluminismo, menoridade intelectual significa a incapacidade humana de se servir da própria razão, requisitando opiniões alheias para a formação dos próprios juízos, privando-se do próprio direito natural da liberdade. Do ponto de vista do Iluminismo, a liberdade exige a autonomia plena da razão. Em estado de menoridade, os indivíduos, impedidos de pensar por si próprio e ouvir as recomendações de sua consciência individual esclarecida, pedem tutoria e controle alheios, prendendo-se àquele que ilumina suas opiniões, criando amarras para seu pensamento.

Nos debates que circulavam no movimento ilustrado do século XVIII, a ação do Estado no campo educacional despontava com proeminência. Para muitos iluministas, a democracia e a educação se supõem e se atraem. Apenas uma educação racional estendida a todos poderia produzir os frutos de igualdade, de justiça e de liberdade, ou seja, as virtudes democráticas por excelência. Nesse esquadro, a instrução pública deveria promover a equidade, a razão autônoma e o primado da diferença de talentos sobre a diferença de fortunas.

Esses princípios deflagrados pela modernidade tornaram-se referência para projetos e parâmetros reformadores da instrução pública em vários dos países da Europa e das Américas a partir do século XIX. Particularmente no Brasil, nos processos desencadeados com a Independência e depois com a República, foram significativos os esforços de reformas da instrução pública. Nos séculos XIX e XX, criaram-se projetos voltados para a constituição de uma escolarização laica, gratuita, pública, para ambos os sexos e universalizada. No entanto é preciso considerar que esses princípios gerais não se efetivaram da mesma maneira, ou seja, de forma homogênea em todos os países e regiões de cultura ocidental que neles se inspiraram.

Cabe-nos questionar como foi que, no Brasil, aqueles ideais se concretizaram; mais ainda, qual foi o sentido atribuído a eles durante a primeira República. Sim, pois os educadores e reformadores da Primeira República, com base nas demandas de seu momento histórico, apropriaram-se dos ideais da modernidade, dando-Ihes um caráter singular, muito diferente do que foi idealizado no século XVIII. 


\section{PROJETO DE EDUCAÇÃO MODERNA NO BRASIL DURANTE A PRIMEIRA REPÚBLICA}

Convém esclarecermos: ao mesmo tempo em que os princípios gerais que nortearam os projetos e as políticas públicas de instrução na contemporaneidade encontram pontos de referência naquele movimento maior, também se diferenciam dele. São diferenças que decorrem das novas questões históricas que surgem na contemporaneidade; ou seja, cada tempo re-significa aqueles princípios, atribuindo Ihes novos significados. Também o contexto cultural brasileiro cria estratégias para implementar o projeto de escola pública, laica e gratuita, imprimindo a esses princípios a marca de sua singularidade.

Importa assinalarmos que, embora as discussões em torno da escola pública antecedam à República, neste capítulo o recorte é pontual. O que queremos é refletir sobre a seguinte pergunta: o que nesse período da Primeira República (1889-1929) brasileira se discutiu e arregimentou em torno da organização de um modelo de escolarização pública?

A Primeira República caracteriza-se por inúmeras reformas da instrução pública, contudo os resultados a que chegaram essas reformas foram localizados, limitando-se a cada Estado ou a cada escola. Assim, se podemos assinalar que os resultados e muitas das intenções foram diferentes, o que teria mobilizado essas reformas a ponto de caracterizarem um momento da história da educação brasileira; o que existiria de comum em suas preocupações? Observemos os dizeres de Lobato (1918, p. 15) ao se referir à população do campo: "Este funesto parasita da terra é o caboclo, espécie de homem baldio, [...] inadaptável à civilização, mas que vive à beira dela [...] Encoscorado em uma rotina de pedra, recua para não adaptar-se". Atentemos também para os termos com que Couto (1925, p. 701), ao discutir o que julgava ser o principal problema social brasileiro, define o analfabetismo. Este não era, para ele, apenas um fator considerável das doenças, "[...] senão uma verdadeira doença, e das mais graves. [...] o analfabeto contrapõe o peso morto de sua indolência ou o peso vivo de sua rebelião a toda ideia de progresso [...]".

Esses fragmentos nos auxiliam a pensar a base em que foi discutida a difusão do ensino elementar durante a Primeira República. Monteiro Lobato (1918), ao representar o homem do campo como arredio à modernização, e Miguel Couto (1925), ao considerar o analfabeto apático à ideia de progresso, remetem-nos a uma das principais preocupações dos reformadores da época. Para esses intelec- 
tuais, a instrução, o ensino e a escolarização eram pensados como instrumentos para generalizar as práticas higienistas, reformar hábitos e reduzir as consequências sociais da pobreza. O caráter regenerador da educação foi observado por muitos. Difundir a educação a toda população era mudar suas práticas e mentalidade, construir valores civis e republicanos e assegurar a sobrevivência em um mundo cada vez mais letrado. Tratava-se, acima de tudo, de homogeneizar as referências sociais do país.

A preocupação com a educação popular pode ser interpretada, de modo geral, como a manifestação do desejo de construir uma unidade para a nação. Nada o demonstra mais claramente do que os empreendimentos realizados pelas reformas educacionais da Primeira República. A documentação que as diferentes administrações estaduais reuniram é portadora dessa forma de entendimento. Os relatórios administrativos de diretores gerais de ensino, os documentos estatísticos, as correspondências oficiais, os artigos de periódicos, os relatos de reformas e compêndios de pedagogia, apesar de variados, apresentam aspectos comuns. Revelam, por um lado, a preocupação ou o desconforto com uma cultura de resistência às ideias progressistas desses reformadores e intelectuais. Por outro, assumem, de modo geral, o discurso da construção da identidade nacional com base nos ideais civis, (des) qualificando práticas sociais diferentes.

De qualquer maneira, é um período no qual surgem novas instituições, cuja organização administrativa revela os objetivos científicos recentemente estabelecidos. As reformas partilharam a tarefa de normalizar, profissionalizar e sistematizar a escolarização das camadas populares. Ao mesmo tempo, tinham como objetivo homogeneizar costumes, hábitos e quereres, delineando um sistema de ensino dirigido e controlado, de forma a produzir a unificação da nação brasileira.

\section{A FUNÇÃO DISCIPLINAR DA EDUCAÇÃO ESCOLAR}

Podemos observar que o pensamento educacional da época orientou-se no sentido de articular o ensino à criação de uma nova cultura nacional, fundamentada nas noções de civismo. A escola pensada por Sampaio Dória (1883-1964), por exemplo, seria o local propício para habituar e para forjar a formação dos comportamentos cívicos. Assim, esse educador se inseria no debate e nas demais campanhas de democratização do ensino do período, as quais comungavam os objetivos de uma alteração e de uma padronização dos comportamentos e dos valores sociais. Logo, quando o aluno fosse à escola, aprenderia a ler e a escrever por meio de lições dis- 
tintas, mas todas carregadas de valores morais e de civismo. Nos bancos escolares é que a cultura cívica seria disseminada, e a nossa tradição republicana forjada.

No depoimento do professor Francisco Azzi (apud AZEVEDO,1937, p. 30), lente catedrático da Escola Normal da cidade de Casa Branca, consta que caberia à escola realizar a unidade, a coesão, a assimilação e a confraternização de todos os indivíduos que por ela passassem, incutindo o espírito brasileiro e humano que a deveria animar. "Tudo poderia concorrer para isso, na escola, desde a arquitetura, a decoração, o ambiente, o ensino, até as festas, os jogos e as relações sociais de toda natureza" (AZZI, apud AZEVEDO , 1937, p. 30).

Almeida Junior (apud AZEVEDO, 1937, p. 45), em resposta à enquete realizada em 1926, também asseverava que "todo o ensino, o de leitura, o de história, o de geografia, o de ciências físicas e naturais" deveria "impregnar-se dessa noção"; da mesma forma, tanto o espaço físico como os momentos de lazer escolar deveriam contribuir para aquele fim.

A busca incessante pela unidade, por estabelecer identidades, parece ser uma preocupação comum aos reformadores na Primeira República. A questão era levar um projeto político de um grupo a ser aceito e incorporado pela maioria, pois disso dependia a consolidação democrática. Instalada a República, os governantes- representantes do poder oligárquico modernizador -, investiram na criação de um sistema escolar modelar. Os republicanos tinham diante de si o desafio de desenvolver a democracia, ou seja, o da participação popular na construção social, o que levará os governos e os intelectuais a defenderem a escola pública para todos, mesmo para aqueles que a escola pouco acrescentaria para o seu fazer cotidiano e para a ocupação que Ihe traria o sustento. Como afirma Vicent (2001, p. 14), a escola se coloca como um investimento de ordem pública pensada para todas as crianças ricas e pobres, com o intuito de não reduzi-las "a simples ato de dominação".

Sampaio Dória (1924, p. 109) relata que, quando pensava nos princípios democráticos e observava a ignorância popular, uma descrença lhe assaltava o espírito: "como organizar-se, por si mesmo, politicamente, um povo que não sabe ler, não sabe escrever, não sabe contar?" De seu ponto de vista, sempre que a cultura fosse escassa, a vontade seria oscilante, sem destino e sem objetivo. "Eduque-se, porém, o povo, e ele compreenderá a soberania que lhe cabe exercer".

O analfabetismo era um problema não apenas do governo, mas de todos, por que de sua solução dependia, segundo os propósitos da época, "o cimento da estabilidade”. As campanhas pela alfabetização - como postula Carvalho (1988, p. 
4) - situam-se "no âmbito de uma vasta empresa de reforma dos costumes que aliava médicos, higienistas e engenheiros aos educadores". Nesse âmbito, a educação era entendida não apenas como um meio para se instruir sobre a Pátria e seus símbolos, mas para habituar os escolares à prática da moral cívica. Como adquirir esse hábito?

O cotidiano escolar foi tomado por inúmeros preceitos que pretendiam ensinar uma nova forma de obediência às regras. Os manuais de Educação Moral e Cívica fixavam, com rigor, cada detalhe da conduta social pretendida. As práticas instituídas visavam a um aprendizado que fortalecesse o sentimento de responsabilidade, de consciência e de firmeza.

Segundo Fernando de Azevedo (1925, p. 38), o objetivo primordial de um educador é criar costumes necessários a uma democracia: "o sentimento da responsabilidade pessoal e o self-government da consciência". Habituar as crianças a deliberar livremente, ou seja, a medir as consequências do que resolvem e a exercer ou cumprir as responsabilidades efetivas dos seus atos, só é possível à medida que uma coação corre no plano interior e racional, ou seja, em um plano de autocontrole. Esse plano de formação imprime aos sujeitos uma noção crescente de se sentir no controle da vida.

Nessa perspectiva, a escola primária vai abandonando os procedimentos estritamente disciplinares (como os castigos corporais), para lançar mão de uma cadeia de estratégias que deveriam atuar no plano do julgamento, ou seja, no da disciplina intelectual das crianças e jovens.

Antônio Candeias (1998) ilustra a tendência de controle do povo por meio das escolas e das formas de escolarização a partir do século XVII. No entanto é preciso considerar que esse controle, no transcorrer do tempo, se deu de forma diferenciada. Os processos utilizados pelas "escolas mútuas" até início do século XIX, que utilizaram o método de Bell e Lancaster, por exemplo, assinalam mecanismos de controle por meio da imposição. Um século depois, a escola desejava disciplinar por meio do desenvolvimento do julgamento e da razão, ou seja, do autocontrole.

A nova ordem urbana e a escola projetada para esse meio possuem finalidades explícitas de aculturação. Nelas se pode sentir a imposição ou a predominância e valorização de uma "forma escolar de socialização". Como expõe Vincent (1994), ao estudar a escola francesa - destacando seu papel político, mais exatamente seu lugar na instauração de uma nova relação de dominação -, que o modo de socialização escolar se impôs às demais formas de socialização. Por meio dela, as crianças se tor- 
nariam homens e mulheres aficionados ao seu país, submissos não pelo temor, mas pela razão, à autoridade, solidários com os demais e acostumados a reconhecer e a respeitar a justiça. Esse novo mecanismo de controle, feito de racionalidade, pode ser observado nas intenções estruturadoras da escola primária da Primeira República brasileira, destinada a todas as camadas sociais. Como bem observa Chervel (1990, p. 179), "deseja-se, de agora em diante, disciplinar. Disciplinar a inteligência das crianças, isto constitui o objeto de uma ciência especial que se chama pedagogia".

\section{A ESCOLA PRIMÁRIA E A CONSTRUÇÃO DA IDENTIDADE DE NAÇÃO}

A institucionalização da escola primária e a produção do saber escolar vincularam-se ao projeto de constituição de nossa nacionalidade. A unidade da língua, dos costumes e das tradições seria um ponto fundamental para unificação do povo brasileiro, naquele momento estilhaçado não apenas pelo grande contingente de imigrantes, mas também pelo que envolve a quebra da continuidade de uma tradição assentada no modo de vida monárquico e a necessidade de conferir legitimidade à vida republicana.

As políticas de imigração no Brasil implementadas a partir do século XIX, quando se deu a substituição do trabalho escravo pelo trabalho livre, criaram uma sociedade multicultural, dando contornos singulares à nação brasileira. Também é verdade que o elemento estrangeiro era elemento de real preocupação para a nacionalidade, em um período entre guerras. A cultura diversificada do imigrante desafiava o projeto homogeneizador da escola pública e as investidas para se instituir uma cultura capaz de legitimar a identidade nacional com base na noção republicana.

Se, por um lado, podemos notar intenções comuns, reiteramos que não podemos pensar que as reformas estaduais foram iguais ou que houvesse simultaneidade em sua implementação. Para observarmos os contornos que cada uma delas foi recebendo, seria preciso analisar o próprio fenômeno, in loco. Assim, com base em fontes documentais, precisaríamos nos inserir nos meandros de sua implantação, ou seja, na aceitação, na rejeição e nas modificações imprimidas pelos diferentes agentes da educação às diferentes reformas. Todavia, neste texto, para a realização desse mergulho, vamos nos ater a fontes documentais do Estado de São Paulo.

Nos relatórios anuais dos inspetores e diretores das escolas paulistas ${ }^{2}$, algumas disciplinas ganharam destaque por exercerem a função de desenvolver o julgamento

${ }^{2}$ Estes relatórios encontram-se organizados e publicados em forma de Anuário. 
moral, a identidade nacional e as tradições e memória republicanas. É o caso de Instrução Moral e Cívica, de História e Geografia do Brasil e Língua Pátria.

Nos programas escolares do ensino primário paulista, apesar das diferenças entre os conteúdos das escolas rurais, urbanas e dos grupos, no que tange ao seu aprofundamento e amplitude, não é difícil perceber as finalidades que os guiavam. Com teor civilizatório, a disciplina Instrução Moral e Cívica buscou marcar a superioridade da vida, dos valores e dos governos republicanos em comparação com outras formas de governo. Agregados ao desejo de uma civilidade pueril e honesta, os conteúdos marcaram a grande luta da escola para forjar uma tradição comum, assim como para legitimar o modo de vida e governo republicanos.

Fazendo parte do aspecto formativo da escola, as comemorações, as festas, as homenagens, os desfiles e espetáculos, o hasteamento da bandeira, a entoação do hino nacional, a visita a túmulos, o torneio de boas ações, entre outros, eram rituais que visavam a instituir uma memória coletiva da República. Demonstravam quem e como devia ser lembrado e quem e o que deveria ser negligenciado e esquecido. Nesse contexto, a escola estaria participando na criação de uma tradição coletiva. Como enuncia E. Hobsbawm (1984, p. 9), por "tradições inventadas" entende-se um conjunto de práticas, de natureza ritual ou simbólica, que visam inculcar certos valores e normas de comportamentos por meio da repetição, de forma a estabelecer uma continuidade com um passado histórico apropriado. Esses rituais, por sua vez, impõem novos conhecimentos, valores e hábitos e, acima de tudo, novos sentimentos e sensibilidades.

Podemos afirmar, desse modo, que em acordo com essa prática e tendo em vista que, conforme Carvalho (1987), o movimento da Proclamação da República teve poucas raízes nas camadas populares e precisava de legitimação, a escola se consolidou como terreno fértil para construir o novo universo simbólico republicano.

\section{PARA A REPÚBLICA UMA NOVA INSTITUIÇÃO ESCOLAR}

A Primeira República é assinalada, também, pela propagação do pensamento renovador da educação. Desde a segunda metade do século XIX, mais especificamente 1870, as finalidades educativas do ensino primário foram renovadas e se revelavam por meio de diferentes correntes pedagógicas. Os novos propósitos traçados para a (e pela) escola primária alteravam significativamente sua função. Transformando-se a escola do instruir em escola do educar, repensava-se com profundidade a formação dada ao aluno. 
A crítica à escola primária de instrução e o despontar cada vez mais acentuado da escola como formadora significaram, por um lado, a necessidade de reorganização da escola. Por outro lado, porém, significaram fundamentalmente o (re)inventar da escola como instituição que se impunha às outras. Essa condição Ihe era assegurada por fatores vários, como: a possibilidade de atender às necessidades de um mundo cada vez mais letrado; o estabelecimento de novas modalidades de aprendizagem escolar e social; os novos conteúdos, que a ajustavam às necessidades republicanas; sua forma de socialização, que se impunha às demais; e ainda a possibilidade de estruturação de um amplo projeto de controle e homogeneização cultural das elites. Reinventar a escola significava, dentre outras coisas, formar e disciplinar professores, alunos e familiares; adequar espaços e tempos e eliminar formas mais livres de ensino.

O lugar de centralidade que a escola foi assumindo na vida social pode ser detectado também pelas construções imponentes dos prédios e espaços que representam conforto e modernidade. É importante pontuarmos que, quando o assunto era escola primária, havia, naquele momento, diferentes instituições de ensino público: os grupos escolares, as escolas isoladas, as escolas reunidas, as escolas particulares, subvencionadas ou não, as escolas estrangeiras, além de outras.

No Estado de São Paulo, nas três primeiras décadas da República, houve uma valorização do grupo escolar em relação às demais instituições, ou seja, este era a representação e a materialização do que poderia se entender por modernização no campo educacional. Criado pelo Decreto n. 248, de 26 de julho de 1894, nascido com a República, o grupo escolar era símbolo de modernidade e progresso, representando o rompimento com a antiga escola imperial, cuja representação seria a escola isolada.

As escolas isoladas representavam outro momento da educação e, comparadas aos grupos escolares, à racionalização e ao controle do trabalho que os caracterizavam, pareciam desajustadas. Essas escolas não eram isoladas apenas por serem classes autônomas, mas também por serem unidades de funcionamento. Embora houvesse uma regulamentação que estabelecesse parâmetros para seu funcionamento, elas não apresentavam rigidez, mostrando-se, na maioria das vezes, flexíveis às necessidades locais.

De acordo com Rossi (2003), o horário de funcionamento das escolas primárias paulistas, por exemplo, ficava a critério da autoridade escolar ou obedecia às próprias necessidades do local onde a escola estava instalada. Em depoimento de professoras que lecionaram em escolas isoladas nos anos 1910 e 1920, no Estado de São Paulo, constatou-se também a flexibilidade de funcionamento dos horários 
de aula. Pela manhã, em períodos intermediários ou à tarde, o funcionamento das escolas adaptava-se às situações de transporte, ou aos horários em que o sol, muito quente, dificultava o trabalho das crianças.

A afirmação da superioridade dos grupos escolares pelos inspetores e diretores do ensino paulista pode ser sentida também quando eles avaliavam a situação das escolas reunidas. Situadas, em sua maioria, nas cidades do interior, durante quase toda a década de 1910 essas escolas, embora consideradas em situação de vantagem em relação às isoladas, foram avaliadas como carentes de uma remodelação. Contudo, no Anuário de 1917, Oscar Thompson, o então diretor geral de ensino em São Paulo, referiu-se às escolas reunidas como se estivessem passando por uma situação transitória, até que pudessem se fundir em um grupo escolar. Essas escolas organizavam-se em locais de população pouco densa e, para facilitar o ensino e a fiscalização, quatro ou mais delas eram reunidas na mesma casa. Por meio da Lei paulista n. 1579, de 19/12/1917, criou-se o cargo de diretor escolar para as escolas reunidas, o que não havia antes. A distribuição dos alunos por classe já se fazia de acordo com o grau de adiantamento da turma e ficava a cargo de um professor, característica que já aproximava essas escolas dos grupos escolares.

Rossi (2003) assevera que, no período de 1918 a 1923, em São Paulo, verifica-se o crescimento estrondoso das escolas reunidas. Esses estabelecimentos, mais convenientes ao Estado, eram econômicos e eficientes, com pessoal administrativo limitado e de instalação fácil e barata. Entendia-se que, reunindo várias escolas em um só prédio, sob a direção de um professor, desapareceriam muitos dos inconvenientes da escola isolada. Tornar-se-ia mais intensa a fiscalização do trabalho do professor e haveria um melhor emprego de suas energias, uma vez que, desobrigado dos outros deveres característicos da escola isolada, teria mais tempo para se dedicar exclusivamente ao trabalho de ensino em sua classe, agora seriada. A existência do diretor da escola significava maior assistência pedagógica aos professores e, como consequência, maior orientação ao ensino e uniformização didática. Além de se beneficiarem de uma instalação definitiva, as escolas reunidas corrigiam, também, os defeitos higiênicos das instalações das escolas isoladas.

As escolas reunidas buscavam aliar menores gastos à racionalidade funcional dos grupos. Os grupos escolares foram projetados como "magníficos palacetes" e marcaram um rompimento de concepção, de organização e de funcionamento da escola imperial. Os grupos possuíam um diretor envolvido diariamente com o cotidiano da escola. Se, por um lado, a fiscalização e o controle eram maiores, por 
outro lado, o convívio social possibilitado por esse novo espaço contribuiu para o aprimoramento do trabalho do professor. Os horários de início e término da aula eram seguidos por todos, exigia-se e fiscalizava-se a pontualidade e assiduidade, o espaço físico era projetado para atender aos requisitos de higiene e saúde, a organização das salas por série (uniformidade de classes) substituía a das salas multisseriadas das escolas isoladas, inaugurando outro tempo, um novo espaço e uma nova relação de ensino e aprendizagem.

No mesmo movimento em que a institucionalização da escola primária avançava, tornando mais claros seus propósitos de aculturação como espaço planejado, a educação escolar adquiria supremacia sobre a tradição familiar e as experiências do saber comum. A escola do educar construiu sua prática pedagógica, firmando-se na relação com os demais espaços sociais e, mais do que isso, demarcando a especificidade própria de seu campo. O educar escolar não apenas diferia do educar familiar, mas a ele se opunha. Questionando a milenar estrutura educacional que vigorava na família, o fato é que a forma escolar de educar se impôs às demais e alterou lentamente conceitos e práticas sociais. Por exemplo, a observância aos aspectos psicológicos no processo educativo lentamente suprimiu os castigos corporais também no interior da família.

\section{REFERÊNCIAS}

ANUÁRIO do ensino do Estado de São Paulo: Diretoria Geral da Instrução Pública, 1911-1912, 1913, 1914, 1915, 1916, 1917, 1918, 1919,1920-1921, 1922, 1923. São Paulo: Tipografia Siqueira, $[\mathrm{s} / \mathrm{d}]$.

AZEVEDO, Fernando de. A educação pública em São Paulo, problemas e discussões: inquérito para O Estado de São Paulo em 1926. São Paulo: Companhia Editora Nacional, 1937.

. O segredo da renascença e outras conferências. São Paulo: Nova Era, 1925.

BRASIL. Lei n.1579, de 19 de dezembro de 1917. Coleção das Leis e Decretos do Estado de São Paulo (1892-1920). Tipografia do Diário oficial, [s/d].

. Decreto n. 248, de 26 de julho de 1894. Coleção das Leis e Decretos do Estado de São Paulo (1892-1920). Tipografia do Diário oficial, [s/d].

CANDEIAS, António. Modelos alternativos de escola na transição do século XIX para o século XX. In: SOUSA, Cynthia Pereira; CATANI, Denise Barbara (Org.). Práticas educativas, culturas escolares, profissão docente. São Paulo: Escrituras Editora, 1998. p. 131-141.

CARVALHO, José Murilo. Os bestializados: o Rio de Janeiro e a república que não foi. São Paulo: Companhia das Letras, 1987. 
CARVALHO, Marta Maria Chagas de. Notas para reavaliação do movimento educacional brasileiro (1920-1930). Cadernos de Pesquisa, São Paulo, n. 66, p. 4-11, ago. 1988.

CHERVEL, André. História das disciplinas escolares: reflexões sobre um campo de pesquisa. Teoria \& Educação, Porto Alegre, n. 2, p. 177-229, 1990.

COUTO, Miguel. A educação popular. Educação, Rio de Janeiro, v. 10, n. 5-6, p. 13- 15, 1925.

DORIA, Sampaio. O espírito das democracias. São Paulo: Editora Monteiro Lobato, 1924.

HOBSBAWM, Eric; RANGER, Terence. A invenção das tradições. Rio de Janeiro: Paz e Terra, 1984.

KANT, I. Resposta à pergunta: que é o lluminismo? (1784). In: KANT, I. A paz perpétua e outros opúsculos. Lisboa: Edições 70, 1989.

LOBATO, Monteiro. Urupês: contos. São Paulo: Revista do Brasil, 1918.

ROSSI, Ednéia Regina. Insuladas tribos - a escola primária e a forma de socialização escolar: São Paulo (1912-1920). 2003. Tese (Doutorado em História)- Universidade Estadual Paulista Júlio de Mesquita Filho (Unesp), Assis, SP, 2003.

VINCENT, Guy et al. Sobre a história e a teoria da forma escolar. Texto extraído do original francês da obra coordenada por Guy Vincent L'éducation prisonnière de la forme scolaire: scolarisation et socialisation dans les sociétés industrielles. Lyon: Presses Universitaires de Lyon, 1994. p. 11-48. [Texto xerografado].

VINCENT, Guy; LAHIRE, Bernard; THIN, Daniel. Sobre a história e a teoria da forma escolar. Educação em Revista, Belo Horizonte, n. 33, jun. 2001.

\section{Sobre a autora:}

Ednéia Regina Rossi: Graduação em Pedagogia e Mestrado em Educação pela Universidade Estadual de Maringá. Doutorado em História pela Universidade Estadual Paulista Júlio de Mesquita Filho. Atualmente é professora associada da Universidade Estadual de Maringá, com atuação na graduação em Pedagogia e no Programa de Pós-graduação em Educação. E-mail: edneiarossi@uol.com.br

\section{Recebido em março de 2017.}

\section{Aprovado para publicação em junho de 2017.}


